\title{
Industrial technologies of the residential buildings reconstruction of the first mass- produced series
}

\author{
Aleksandr Afanas'ev ${ }^{1, *}$ and Aleksandr Kurochkin ${ }^{2}$ \\ ${ }^{1}$ Grand Ph.D in Engineering, Prof., A.M. of RAACS, Moscow State University of Civil Engineering, \\ Jaroslavskoe Shosse 26, Moscow, Russian Federation \\ ${ }^{2}$ Ph.D in Engineering, 105318, LLC “InTechProject", Mironovskaya ul., 25, Moscow
}

\begin{abstract}
The article dwells upon the reconstruction technologies of the residential buildings of the series that are not subjected to demolishing by way of superstructing of the attic floors and standard floors made of unitized folding units, adding of lifts, unitized elements of kitchens, living rooms and loggias. Their application makes it possible to increase the areas of kitchens by $6.0 \ldots 8.2 \mathrm{~m}^{2}$, of bedrooms and other premises - by 3.5-4.2 $\mathrm{m}^{2}$. The technology of the attic units manufacture under plant conditions has been worked out. It has made it possible to optimize the design concept of the articulated joints, ensuring the transport adaptability due to flatwork elements folding. The technologies of the high-speed superstructing and building up of the buildings, using line production of works have been investigated.
\end{abstract}

The moral and aesthetic depravity of the five-storey residential development gets worse by the fact that the only type of the sectional house has been realized without regard to the demographical and architectural traditions of the districts and climatic conditions.

It is worth noting that in spite of enough high structural reliability of five-storey buildings, they have small reconstructive capability. It relates to residential panel houses the interior wall of which are bearing ones and are located with a narrow pitch of 2.6 and $3.2 \mathrm{~m}$. [1].

The RF Government and the Moscow Government has taken a decision to demolish the five-storey housing stock.

The first program of the five-storey buildings demolishing is being completed. 160 thousand families have been rehoused in the course of its implementation.

According to the new program it is presupposed to demolish more than $20 \mathrm{mln} \mathrm{m} \mathrm{m}^{2}$ housing accommodations, it is meant for 15-20 years. $1 \mathrm{mln}$. and 800 thousand dwellers will get the new modern housing accommodations.

\footnotetext{
*Corresponding author: 7450688@gmail.com
} 
The new flats' area will be bigger by $20 \%$ than the area of the residential premises, what will make it possible to increase to the regulatory values the kitchens, lavatories, corridors, loggias or balconies [3].

At the same time, it should be noted that a part of the five-storey buildings of the series that are not subjected to demolishing can be reconstructed. Due to lack of funds in the RF regions, the primary way of the obsolescence and physical deterioration liquidation is reconstruction without the dwellers being rehoused.

Possessing of the high obsolescence, low performance characteristics and low-level architectural and planning standard, such housing stock needs full-fledged rehabilitation through comprehensive reconstruction, with due regard to the modern requirements lodged to the housing accommodations [4-6]. The annual physical deterioration deepens the obsolescence process of the buildings and approximates to the emergency condition.

The characteristic traits of the obsolescence are the following ones: small dimensions of the kitchens (4.0-6.0 $\mathrm{m}^{2}$ ), entranceways, utility cores; absence of lifts and rubbish ducts; discomfort of the residential premises due to disturbance of humidity conditions and sound insulation; big physical depreciation of the utility networks; high heat losses through the building envelopes resulting in multiple excess of the energy carriers consumption [7].

The technical and economic study, the foreign and domestic reconstruction experience of the residential houses having few floors shows that the most effective is the superstructing with few floors (1...2 floors) and adding of small volumes to the elements of the buildings. Such concept excludes a cycle of works for shoring of foundations and other elements of the buildings, what reduces significantly the prime cost of the additional areas and makes it possible to perform the reconstructive works without or with partial rehousing of the dwellers [2].

The conceptual basis of the buildings reconstruction of the first mass-produced series is the development and creation of highly industrial flexible technologies based on use of the conceptually new unitized elements of factory production. Such concept makes it possible to turn the technological reconstruction process into the assembly and integration cycle and to reduce many times the works duration.

The design concept provides for the use of several types of the unitized units: one-/doublelevel - for superstructing of the buildings (fig.1), of bay window type - for adding, aimed at obtaining of additional areas for kitchens and living rooms; of special units - for adding of lifts (fig.2). The main requirements to the unitized units for superstructing and building up of the buildings is a high level of the factory readiness, reducing to a minimum the works volumes at a construction site, ensuring the transport adaptability and serviceability. An additional requirement to the units being superstructed is an ability to the dimensional instability owing to the articulated joints use, what ensures the transport adaptability and an ability to obtain the different geometry of the floors being superstructed.

The project designs for the residential houses reconstruction of series 1-464, 1-447, 1$510,1-515$ and others, have shown that the adopted technology use provides for the total areas increment in the following range:

- adding of unitized bay windows

$-19.4 \ldots 20.6 \%$

- adding of unitized bay windows and superstructing of the attic floor $\quad-42.6 \ldots 50.3 \%$

- adding of the unitized units along the perimeter of the buildings $-70.5 \ldots 72.8 \%$ with superstructing of a full and attic floors

One- and double-storey unitized units have been developed, ensuring the superstructing of the residential buildings of different series with the attic floors, with one full and attic floor. Thereby, the overall dimensions of the units are adopted according to a pitch of the interior bearing walls for large-panel buildings and which is multiple of the window areas placement for the buildings with brick walls. The outstanding feature of such systems is an 
opportunity to obtain a space of hall type, what ensures a flexible planning of the floors being superstructed.

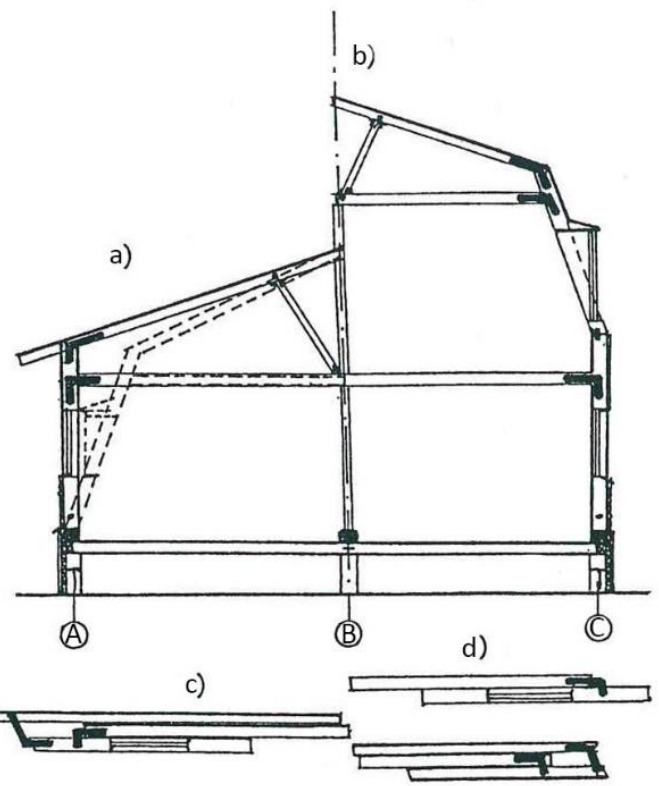

Fig.1. The basic diagrams of one-storey (a) and double-storey (b) of the folding unitized units for superstructing of the buildings; (c, d) - the transport position of the units.
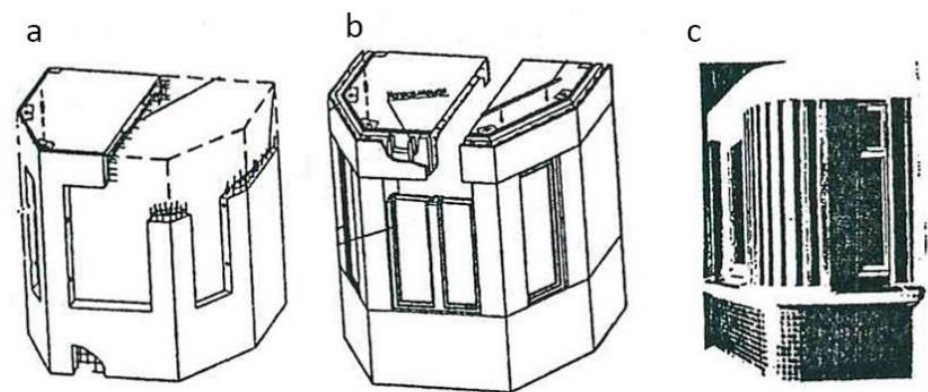

Fig.2. The structural scheme of the added-on unitized units.

$\mathrm{a}$ - non-heat insulated loggia unit; $\mathrm{b}$ - unit with 3-layered exterior walls; $\mathrm{c}$ - overall view of a readyto-operate unitized unit.

Use of the composite structures of metal, slabby and casting heat insulator, heavyweight concrete and lightweight concrete has resulted, beside the total mass reduction - in increase of the heat and sound insulation indicators. For the unitized units of the floors being superstructed metal consumption amounts to $24 \ldots 26 \mathrm{~kg} / \mathrm{m}^{2}$ of the area.

The added-on unitized elements of different geometrical shape have been worked out for the buildings of different framing schemes: the kitchen units with the area of 4.5..6.08 $\mathrm{m}^{2}$; bay window blocks to increase the rooms' area $3.5 \ldots 4.6 \mathrm{~m}^{2}$; the loggias' blocks $-3.2 \ldots$ $4.3 \mathrm{~m}^{2}$, what ensures a diversity of the architectural solutions and an opportunity to avoid attribution to a certain classification type [2]. 
The architectural and planning solutions for reconstruction of a three-section residential house with brick walls is specified in fig.3, where a standard block with the area of $8.2 \mathrm{~m}^{2}$ with three-layered wall structures, complying with the thermotechnical requirements as well as the blocks of the lift shafts are used as building extensions along the perimeter of a building.

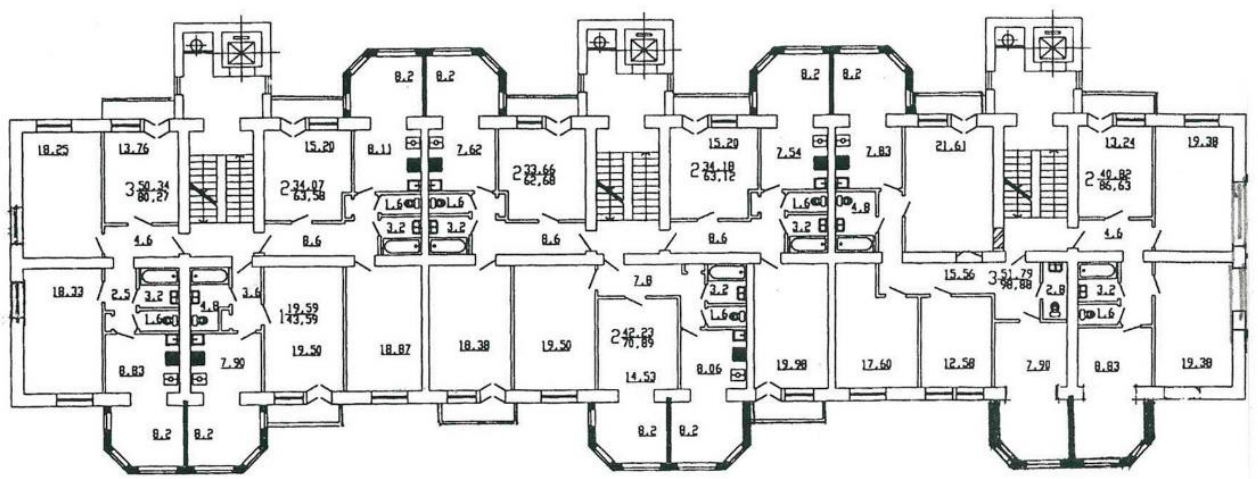

Fig.3. Plan of a standard storey with addition of the unitized units.

In fig. 4 there is a layout of an attic block after opening and assembly of half blocks, installation of a translucent window block, envelopes. Pre-assembly can be carried out in immediate proximity to a facility under reconstruction, as well as at an individual site.

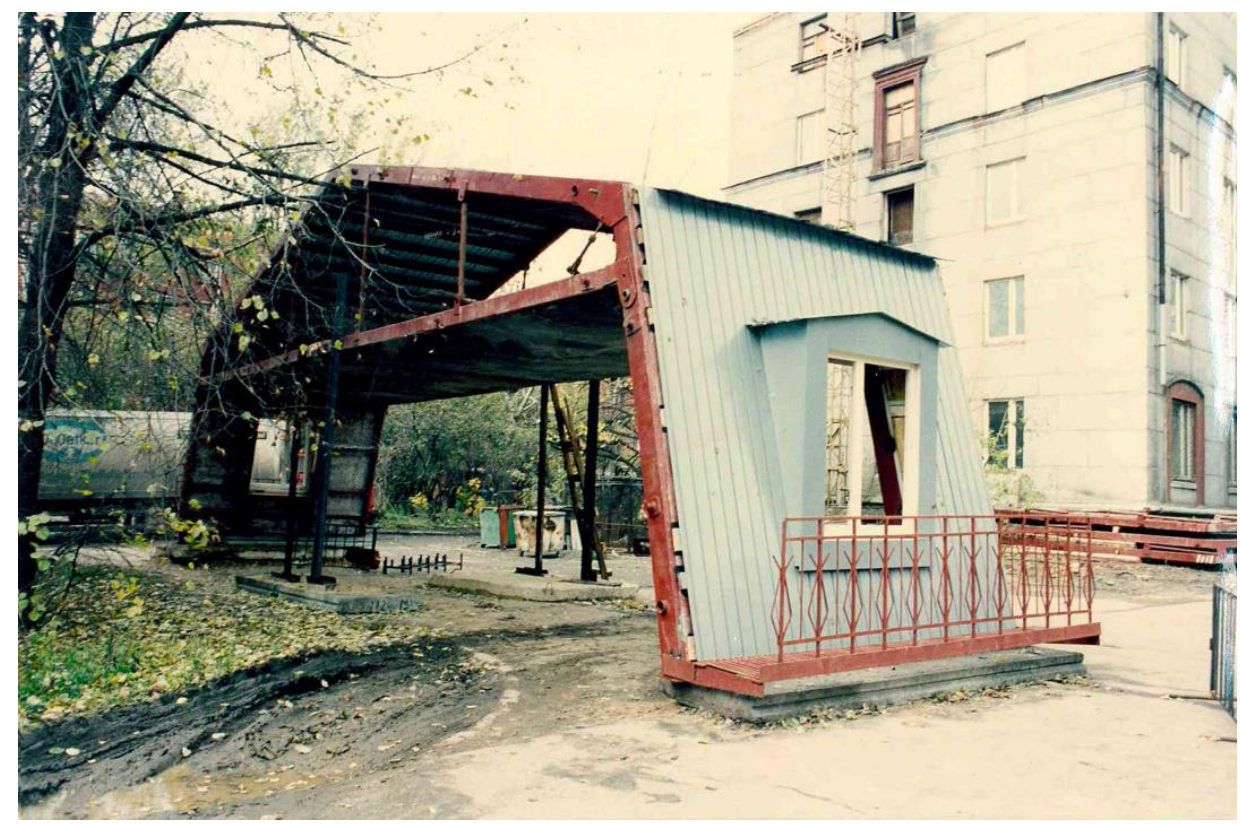

Fig.4. Overall view of an attic unit after pre-assembly.

The comparative data for reconstruction with superstructing of attic floors according to the traditional technology and the unitized units have shown the unit labor costs reduction by 68 times under building conditions and prime cost reduction for $1 \mathrm{~m}^{2}$ of the area - by 26$30 \%$. 
A special site is used for pre-assembly, where opened half blocks are installed successively, are united in the central zone by means of the bolted-type connections and welding. A special team of the installation fitters takes part in the work.

The technological stages of the works production include several construction flows that are consistent in time.

Prior to perform the installation works of the unitized units, the zero works cycle is performed that consists in basement work for added-on volumes in form of short bored and cast-in-place piles and grillage beams. A cycle for the monolithic girt creation in a parapet part is implemented in parallel to these works for a subsequent placement on it of the units of the attic floor.

The erection technologies of the floors being superstructed using the methods of the half blocks installation and unitized elements enlarged to a span, as well as their launching, have been worked out.

When building up the buildings with the unitized elements and superstructing with an attic floor, the most reasonable is the works performance when two construction flows are formed, one of which produces the cycle of superstructing, and the other one - installs the added-on volumes from the transportation facilities.

When reconstructing large-panel buildings to perform the building up works, dismantling of the external wall panels is required that is fulfilled by a separate technological flow.

To install the blocks of the attic floor, jib-type crane Liebherr LTM 1160 with the telescopic jib is used, with the lifting capacity at a working radius of operation of $24 \mathrm{~m} \mathrm{-}$ 14.6 t. Mass of the blocks being installed with the width of 3.2 and $2.6 \mathrm{~m}$ amounts to 7.2 and $8.4 \mathrm{t}$.

For the pre-assembly of the attic units, truck crane with the telescopic jib with the lifting capacity of $10 \mathrm{t}$ (fig.5) is used.

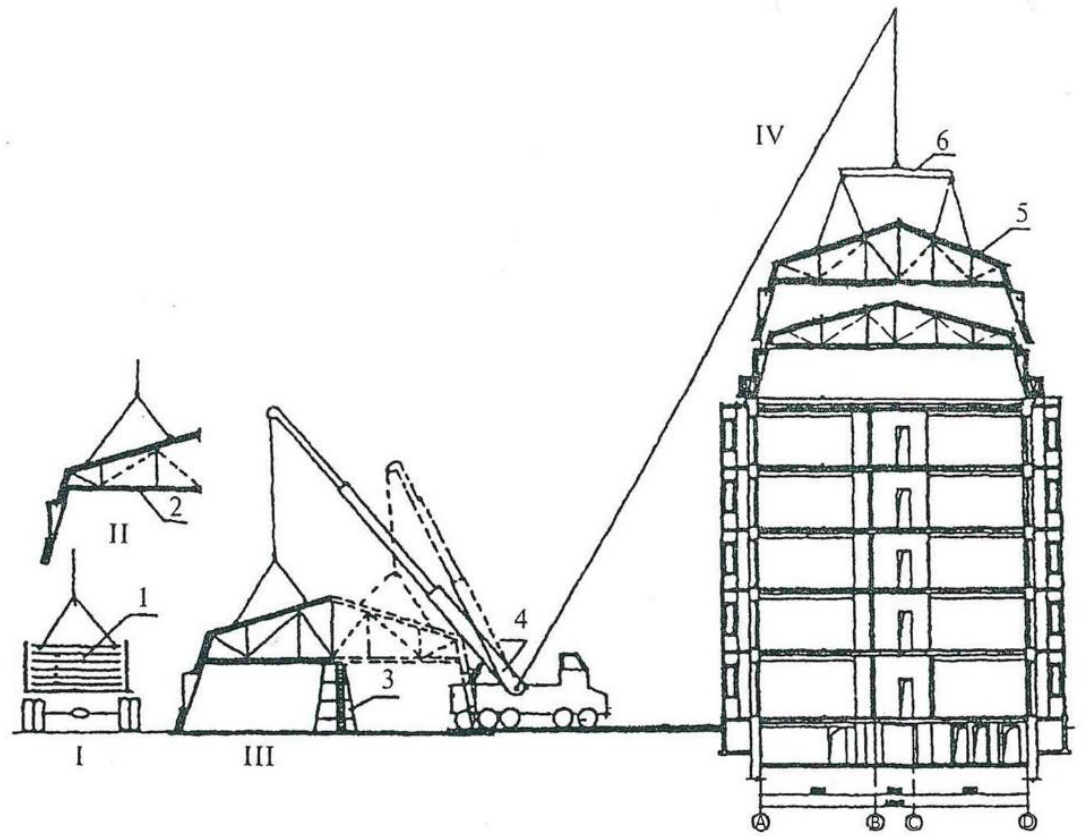

Fig.5. Technological schemes of the units enlargement and their installation. 
I - transport facility with volumetric sides; II - opening of units; III - pre-assembly at a guide; IV installation of a unitized unit to a bay of a building; 1 - units in a transport position; 2 - opened unit; 3 - supporting platform; 4 - motor crane; 5 - unit within an installation period; 6 - cross arm.

The works performance technology includes three cycles: transportation, pre-assembly and installation of the unitized units.

Taking into account a construction site's lack of space, two zones of the pre-assembly are created, what ensures an estimated consistency and duration of the installation works and associated works.

While installing the attic units, the works cycle for installation of end walls, stairways, lift shafts, interior planning works is fulfilled.

The detailed study is given in the technological documentation in form of the works production plan, flow diagrams and special calculations.

The exploratory tests have been carried out through superstructing with the attic units of 80-flat 4-section residential house. In standard labor intensity of one unit installation 6.8 people/hour and membership of the installation fitters' team 5 people, the works duration at one grip (6 units) amounts to 16.8 people/hour. The total installation duration of the attic units has amounted to 8.5 machine-shifts of the crane work. The total erection duration of an attic floor and the associated works duration has amounted to 70 working days. Thereby, an additional area of about $870 \mathrm{~m}^{2}$ has been obtained.

When using 2-storey unitized units (fig.6), they apply more powerful cranes Lakomo A395NR, special systems of slinging operations with the remote removal of slings, and means ensuring stability of geometrical shape of a unit in the process of hoisting.

To reduce transport costs, pre-assembly is done in the zone of the main crane operation with the use of motor crane KS-3577. Special supporting platforms with the hydraulic jacks are used to align the mating elements of the lower and upper storeys to the permanent location and to fix them in the permanent location. In the course of the pre-assembly, the works quality control is exercised and compliance with the design concept is made. 


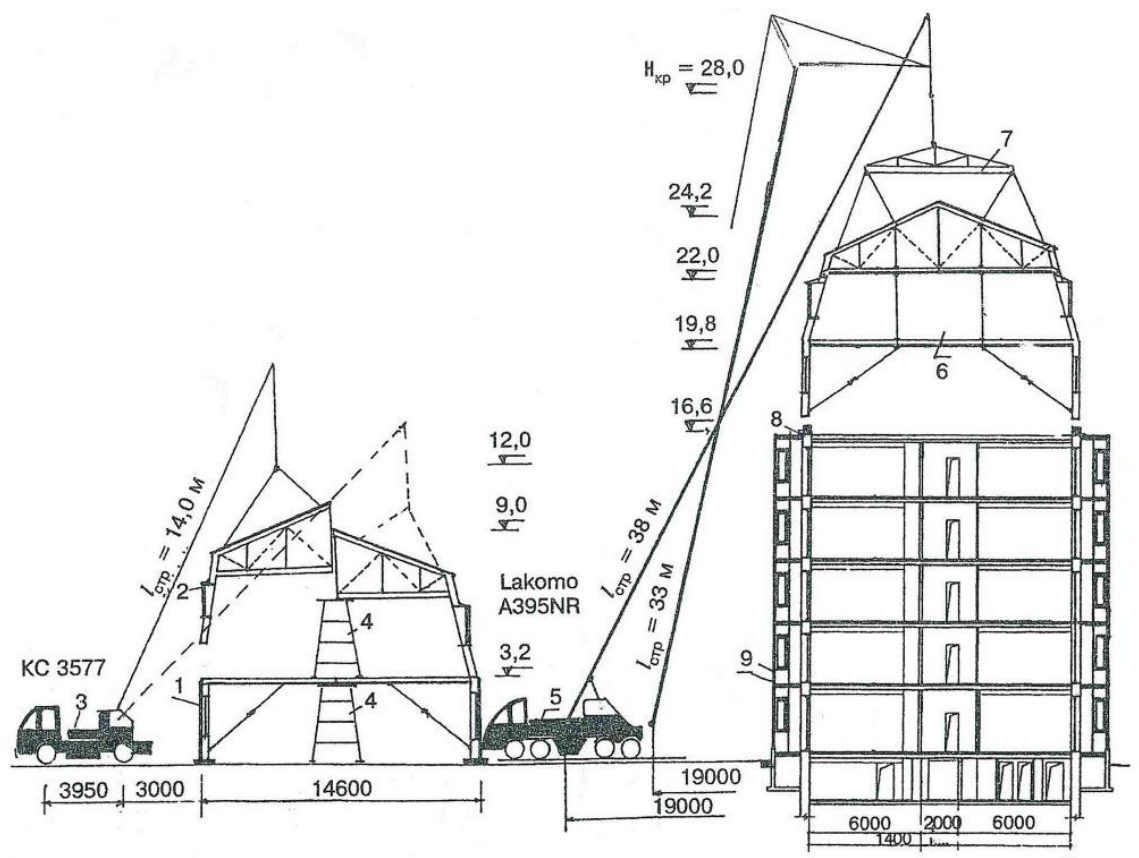

Fig.6. Technological schemes of pre-assembly and installation of 2-storey unitized units to superstruct the buildings.

1 - a unitized unit of a storey being superstructed; 2 - the same of the attic floor; 3 - jib-type crane with the telescopic jib for pre-assembly; 4 - supporting platforms; 5 - jib-type crane Lakomo to install 2-storey unitized unit; 6 - a unitized unit in an installation position; 7 - cross arm; 8 - a monolithic girt; 9 - installed bay windows.

Erection of 2-storey superstructures needs the use of not only more powerful cranes but also actions for ensuring safe production of works, spatial rigidity and stability, fencing of working places etc.

Optimization of the installation processes is made through the cost estimation of the works performance with due regard to the factors of erection cranes' down time or queue formation consisting of the transport facilities for the unitized units delivery, their time of maintenance for pre-assembly and following up. The variants of the models have been dwelt upon in which assembly components are supplied directly below an erection crane, and a model with an interim site - stock for pre-assembly.

The results of the numerical calculation methods have shown that in installation intensity of the unitized units $\mu_{1}=2,0, \mu_{2}=1,5, \mu_{3}=1.0$ unit/hour, the continuous work of two erection cranes will be achieved in terms of the supplying intensity equaling to $3.5 ; 2.7$ and 2.2 units per hour accordingly.

In these values the minimum costs are achieved and the continuous cycle of the installation works performance is ensured and it has the essential value when designing the total term of the building reconstruction.

The building up and superstructing method of the buildings made of unitized elements is universal and can be used for the majority of the mass-produced series of the large-panel and brick buildings. 


\section{References}

1. STO 000433363-01-2008, Reconstruction and modernization of deterioration housing, RAASN (2008).

2. A. Afanas'ev, E. Matveev, Reconstruction of residential buildings, Part I, Part II (2008).

3. S. Bulgakov, Reconstruction of apartment houses of the first mass series, (1998).

4. P. Oleinik, V. Brodskii, Features of the organization of construction in the reconstruction of buildings and structures, TOS, 4(5) (2013).

5. A. Ishin, D. Tumanov, M. Ershov, A. Lapidus, Technological and organizational aspects of building reconstruction, TOS, 3(8) (2014).

6. M. Ershov, G. Gamrekilidze, Reconstruction buildings of the series that are not subjected to demolishing, TOS, 2(3) (2014).

7. M. Ershov, G. Gamrekilidze, A Manin, On the issue of the relevance of the reconstruction and overhaul of residential buildings in the mass construction of 1953-1975, TOS, 4(9) (2014). 